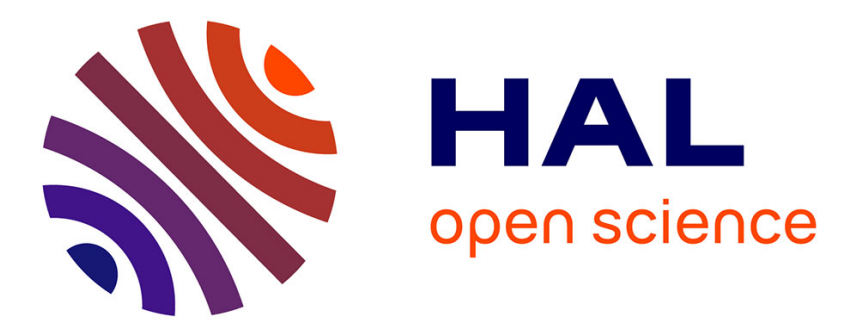

\title{
Experimental study of the stress gradient effect under fretting loading by full field measurement techniques
}

\author{
A.R. Moustafa, Bruno Berthel, Siegfried Fouvry, Eric Charkaluk
}

\section{To cite this version:}

A.R. Moustafa, Bruno Berthel, Siegfried Fouvry, Eric Charkaluk. Experimental study of the stress gradient effect under fretting loading by full field measurement techniques. Wear, 2015, 330-331, pp.160-169. 10.1016/j.wear.2014.12.007 . hal-01200736

\section{HAL Id: hal-01200736 \\ https://hal.science/hal-01200736}

Submitted on 15 Jul 2021

HAL is a multi-disciplinary open access archive for the deposit and dissemination of scientific research documents, whether they are published or not. The documents may come from teaching and research institutions in France or abroad, or from public or private research centers.
L'archive ouverte pluridisciplinaire HAL, est destinée au dépôt et à la diffusion de documents scientifiques de niveau recherche, publiés ou non, émanant des établissements d'enseignement et de recherche français ou étrangers, des laboratoires publics ou privés. 


\title{
Experimental study of the stress gradient effect under fretting loading by full field measurement techniques
}

\author{
A-R. Moustafa*, B. Berthel*, S. Fouvry*, E. Charkaluk**
}

*LTDS, UMR 5513, Ecole Centrale de Lyon, 36 Avenue Guy de Collongue, Ecully 69134 Cedex, France, abdel-rahman.moustafa@ec-lyon.fr, bruno.berthel@ec-lyon.fr, siegfried.fouvry@ec-lyon.fr

**LML, UMR 8107, Ecole Centrale de Lille, boulevard Paul Langevin, 59655 Villeneuve d'Ascq

Cedex, France, eric.charkaluk@univ-lille.fr

Corresponding author: A-R Moustafa (Tel: +33 (0)4 721860 44; E-mail: abdel-rahman.moustafa@ec-lyon.fr)

\begin{abstract}
The improvements in camera technologies and image processing have caused full field measurement techniques to become more and more frequently used in the field of experimental mechanics. Nevertheless, few applications can be found in the field of contact mechanics. Therefore, the aim of this work is to present, a novel experimental set-up based on a coupled kinematic-thermal measurements used for the first time in contact mechanics. A case study of the stress gradient effect based on the crack initiation identification, of a well known $35 \mathrm{Ni}$ Cr Mo 16 low-alloyed steel under fretting loadings, is then presented to validate the predictions by means of this set-up.
\end{abstract}

Key words: Coupled kinematic-thermal measurement, Quantitative InfraRed Thermography (QIRT), Digital Image Correlation (DIC), fretting, stress gradient, crack nucleation.

$\begin{array}{ll}1 & \text { Nomenclature } \\ A_{f} & \text { amplitude of periodic signal at } f_{L} \\ A_{f}^{\text {sta }} & \text { stabilized value of } A_{f} \text { reached after several cycles } \\ A_{2 f} & \text { amplitude of periodic signal at } 2 f_{L} \\ A_{2 f} f^{\text {sta }} & \text { stabilized value of } A_{2 f} \text { reached after several cycles } \\ a & \text { Hertzian contact half size } \\ E & \text { young modulus } \\ f_{L} & \text { loading frequency } \\ f_{S} & \text { camera frame rate } \\ P & \text { constant normal force } \\ p & \text { Hertz contact pressure distribution } \\ p_{\text {max }} & \text { maximal Hertzian pressure } \\ Q & \text { cyclic tangential force } \\ Q_{a} & \text { tangential force amplitude } \\ q & \text { shear stress distribution in the contact } \\ q_{m a x} & \text { maximal value of } q \text { reach during a cycle } \\ Q_{t h} & \text { crack threshold value obtained by the destructive method in } \mathrm{N} / \mathrm{mm} \\ q_{t h} & \text { crack threshold value obtained by the destructive method in } \mathrm{MPa} \\ \mathrm{Q}_{I R} & \text { crack threshold value obtained by the thermal method in } \mathrm{N} / \mathrm{mm} \\ q_{I R} & \text { crack threshold value obtained by the thermal method in } \mathrm{MPa} \\ R & \text { cylinder radius } \\ R_{a} & \text { arithmetic mean surface roughness } \\ \delta & \text { tangential displacement } \\ \delta_{a} & \text { tangential displacement amplitude } \\ \mu & \text { coefficient of friction } \\ \sigma_{\mathrm{u}} & \text { ultimate stress } \\ \sigma_{\mathrm{y} 0.2} & \text { yield stress at } 0.2 \% \\ \sigma_{f r} & \text { fretting stress } \\ \sigma_{f a} & \text { fatigue stress } \\ \theta & \text { temperature variation } \\ \theta_{d} & \text { thermal drift } \\ \theta_{d}^{\text {sta }} & \text { stabilized value of } \theta_{d} \text { reached after several cycles } \\ \theta^{i t} & \end{array}$




\section{Introduction}

Fretting, a localized oscillatory movement that occurs when two contacting surfaces pressed together by external normal force are subjected to cyclic tangential loading. As illustrated in figure 1, fretting can introduce strong heterogeneous stress gradients states, inducing cracking phenomena, which can reduces the endurance of assemblies. Fretting damage has been recognized as a problem in several industrial applications (e.g., helicopters, aircraft, trains, ships...[1]).Taking into account the effects of those gradients on the mechanical behavior is essential for a proper evaluation of structure's life. Considerable progress has been made in the understanding of this phenomenon but the classical identification techniques used [2] remain time-consuming and require expensive destructive methods that render dispersive results. One alternative method based on the material's self heating response was presented for the first time in [3]. It assumes that the temperature evolution of a specimen during a fretting loading can be related to the microplastic behavior and thus an indicator of crack initiation. Material self heating methods were widely used to determine fatigue limits under uniaxial [4]-[7] and multiaxial [8] loadings providing a fast, non-contact identification techniques.

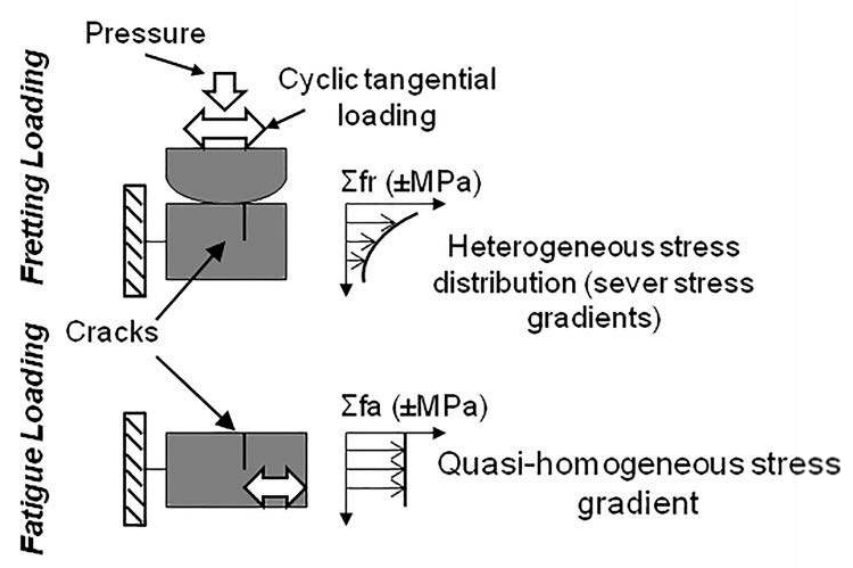

Fig. 1. Illustration of the stress gradient conditions

In this work the development of a novel experimental set-up based on full field measurement techniques such as Quantitative InfraRed Thermography (QIRT) and Digital Image Correlation (DIC) will be first presented.

To our knowledge, four different experimental techniques exist for the coupled kinematic-thermal measurements. The single-face measurement, where both IR and visible cameras observe the same face either by introducing an angle as in [9], [10], or by introducing a dichroic mirror as in the work of [11]. One important problem for this method is the coating for the specimen surfaces, since QIRT uses a uniform high emissive coating, where DIC requires a heterogeneous coating, such as speckled painting.

The one-shot measurement, developed in the works of [12], [13], where a single IR camera is used to measure both kinematic and thermal fields. The main problem with this method is the low-resolution of IR images which will influence the DIC precision. Finally the two-face measurement employed for the first time in the works of [14]-[16]. This technique will be used in this work and details will be given in the next section

This non-contact set-up will then be used for a case study of the stress gradient effect by means of crack initiation identification under various fretting loadings for a well known steel alloy the 35Ni Cr Mo 16.

\section{Coupled kinematic-thermal measurement}

Figure 2 shows the experimental set-up of the two-face measurement used in this work. The main advantage of this set-up is the flexibility to choose the surface coating of each technique separately. Since the two metrologies are performed on two separate surfaces, that will provided good measurement precision. However, two problems involve in this type of measurement, the temporal matching of the two cameras and the spatial matching of the images. 


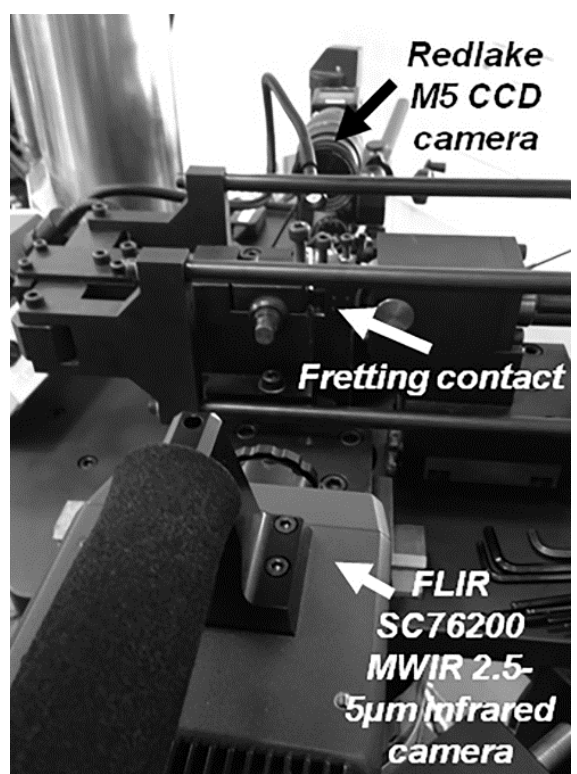

Fig. 2. The two-face experimental set-up matching.

This section will be divided into two parts: temporal matching (cameras synchronization) and spatial

\subsection{Temporal matching}

It is important to understand that each camera has a physical time delay between the moment a trigger signal is given to take an image and the moment of capturing the image. Therefore, the accuracy of the coupled measurement cannot be guaranteed using only a time/frequency analysis as in the works cited above, unless this physical delay is taken into consideration.

For the IR Titanium camera used in this study the time delay was indicated by the manufacturer and an additional time delay can be added if needed using the camera command software (Altair from FLIR). As for the CCD camera this delay was unknown and needed to be tested. Figure 3, shows a sketch of the experiment used to determine this time delay.
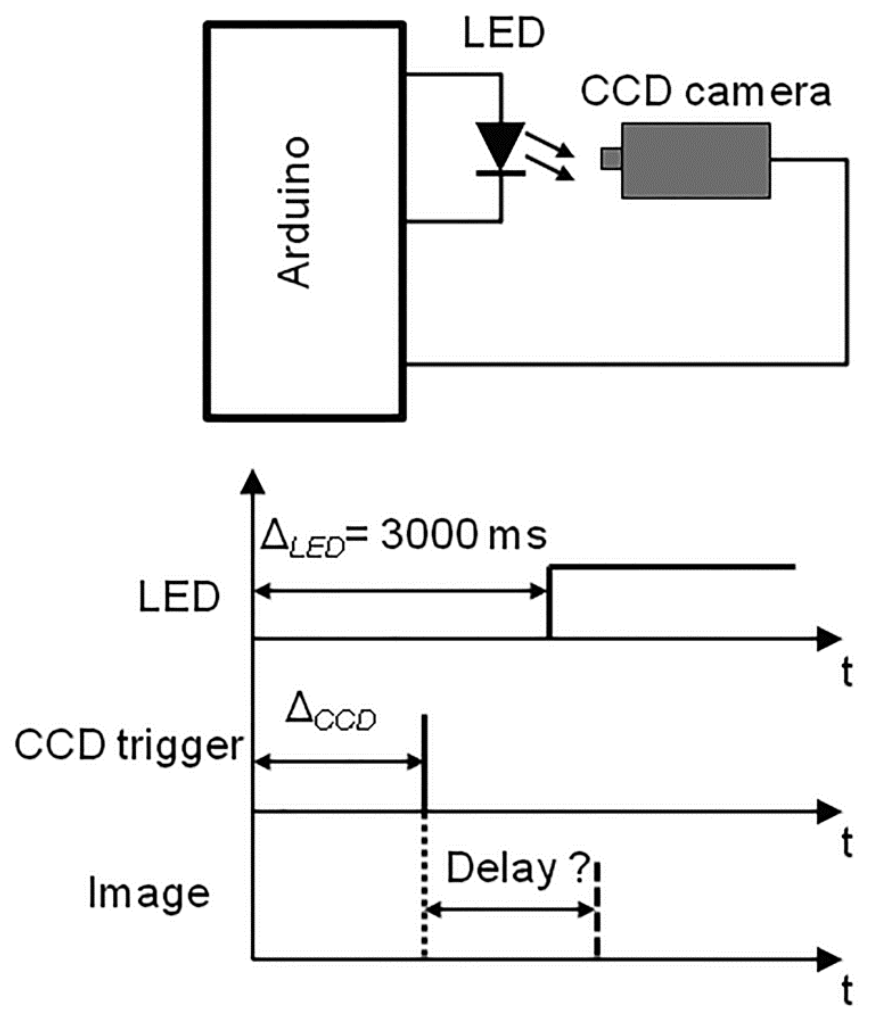

Fig. 3. Experimental sketch of CCD camera time delay determination 
With the micro-controller signals with different time delays can be generated. The delay $\Delta_{L E D}$ is fixed to $3000 \mathrm{~ms}$, and the LED was kept on HIGH mode. The idea is to determine a $\Delta_{C C D}$, which represents the physical time delay of the CCD camera, when an image with a lightning LED is observed. To overcome any delay related to the LED electronics, images taken at different $\Delta_{C C D}$ were compared to two other images taken as a reference. One where the LED is OFF and one where the LED is ON. Figure 4 (a), (b), (c) show images taken at different $\Delta_{C C D}$. Comparison between figure 4(c) and a reference image (figure 4(d)) can lead to the conclusion that the time delay of the CCD camera used in this work is $41 \mathrm{~ms}$. An order of magnitude of $0.05 \mathrm{~ms}$ of error is considered acceptable for this study.

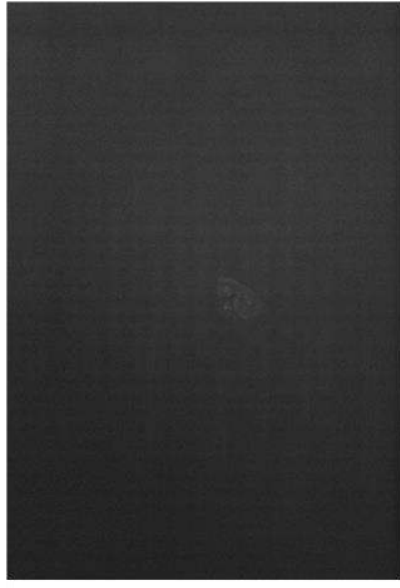

(a)

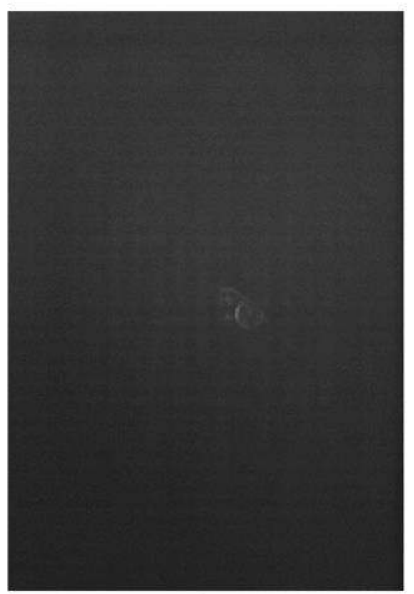

(c)

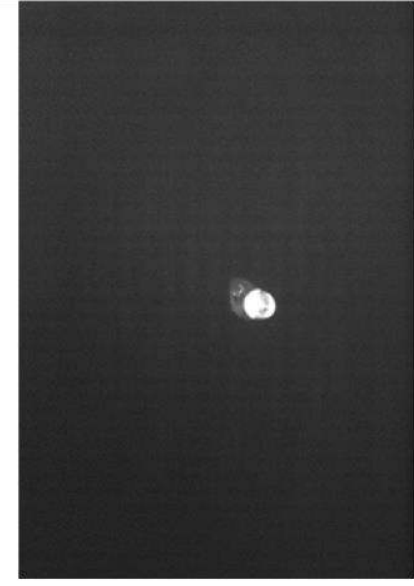

(b)

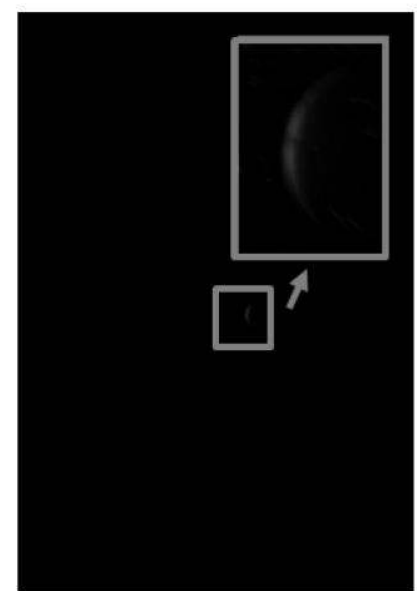

(d)

Fig. 4. Images taken at: (a) $\Delta_{C C D}=2959 \mathrm{~ms}$ (LED is OFF), (b) $\Delta_{C C D}=2961 \mathrm{~ms}$ (LED is ON), (c) $\Delta_{C C D}=2960$ ms (LED is slightly brighten) and (d) difference between image (c) and reference LED OFF image

\subsection{Spatial matching}

In order to achieve a spatial matching on the images acquired by two different cameras, which are not recorded with the same magnification, a transformation function from one space to another is proposed. The most common transformations can be rigid transformation, affine transformation, similarity transformation and B-spline transformation. For this work an affine transformation was used, taking into consideration the most common non-matching effects: rigid motion and projection. The transformation function $\tau$ can then be defined as follows:

$$
\left\{\begin{array}{l}
x_{I R}=a_{x} x_{C C D}+b_{x} y_{C C D}+c_{x} \\
y_{I R}=a_{y} x_{C C D}+b_{y} y_{C C D}+c_{y}
\end{array}\right.
$$

At least three points geometrically identical should be identified on each of the images. The point coordinates are then used to solve (1) with the least square method and $\mathrm{a}_{x}, \mathrm{~b}_{x}, \mathrm{c}_{x}, \mathrm{a}_{y}, \mathrm{~b}_{y}$ and $\mathrm{c}_{y}$ were determined.

Before testing, a reference target (figure 5(a)) is placed at exactly the same position where the specimen should be. The reference target thickness is equal to the tested specimens and have 5 holes. This is will avoid any additional corrections related to the cameras field depth and position. 


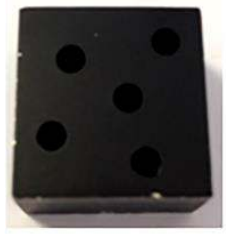

(a)

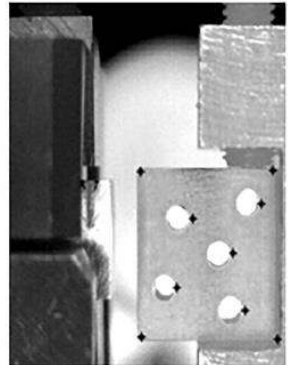

(b)

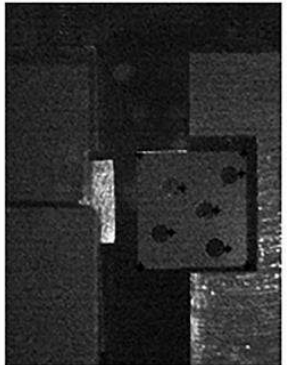

(c)

Fig. 5. (a) Reference target (b) IR image of the target (c) CCD image of the target

The images of the target are then captured respectively by IR and CCD cameras. On each of these images, at least three points were identified (figure 5 (b) \& (c)) and used to determine $\tau$.

\section{Case study}

The aim of this next section is to present a case study using the coupled measurement explained above. Therefore, the cracking nucleation phenomena of a well known steel alloy was studied under various fretting loading conditions, covering a wide stress gradient domain. The results are then compared with those obtained with the conventional identification technique.

\subsection{Materials}

The present work was performed on a $35 \mathrm{Ni} \mathrm{Cr}$ Mo 16 low-alloyed steel, in a cylinder on flat contact configuration assuring a $2 \mathrm{D}$ contact configuration. Cylindrical pads are made from a heat treated steel alloy 100 C6 with a controlled roughness $(\mathrm{Ra}=0.4 \mu \mathrm{m})$, ensuring that cracks arise only in plane specimens and not the cylindrical ones. Table 1 shows the mechanical properties of the specimens used in this work.

\begin{tabular}{lcccc}
\hline Material & $\mathrm{E}(\mathrm{GPa})$ & $v$ & $\sigma_{\mathrm{u}}(\mathrm{MPa})$ & $\sigma_{\mathrm{y} 0.2}(\mathrm{MPa})$ \\
\hline 35NCD16 & 200 & 0.3 & 1130 & 810 \\
100C6 & 195 & 0.3 & 1500 & 813 \\
\hline
\end{tabular}

Table 1. Mechanical properties of the studied specimens.

\subsection{Experimental device}

Tests were carried out using an experimental set-up specially designed at LTDS and mounted on a servo-hydraulic machine. A fretting test consists on applying a static normal force $P$, followed by a cyclic displacement $\delta$, generating a cyclic tangential load $Q$ on the contact zone [17] (figure 6(a)). P, Q and $\delta$ are recorded during the tests and the $\delta-Q$ fretting loop are plotted and monitored to maintain a partial slip contact configuration (figure 6(b)). For each maximal pressure, coefficients of friction at the transition between partial slip and gross slip regimes were previously estimated. Those coefficients may be used to provide representative value of the friction within the sliding zone under partial slip conditions, as it was shown in [18]. 


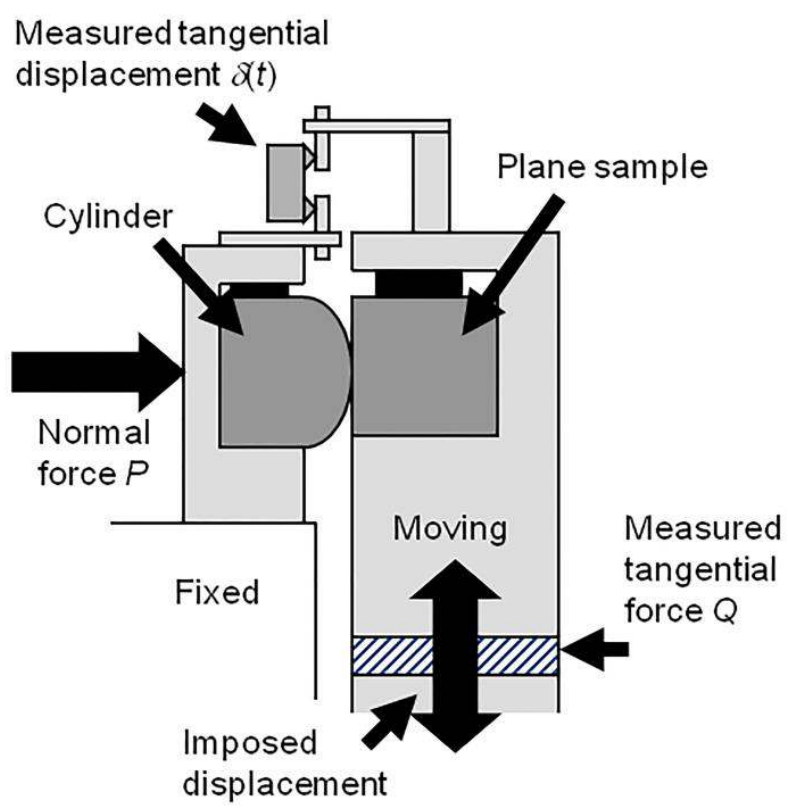

(a)

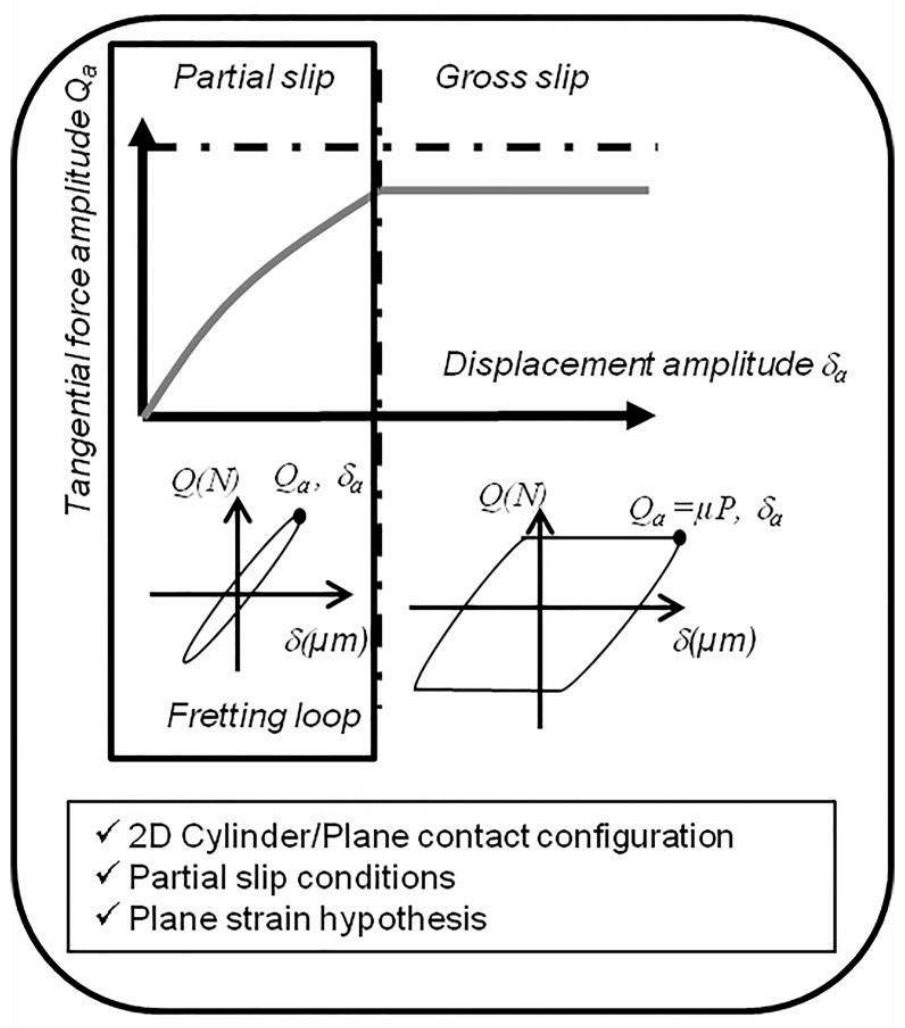

(b)

Fig. 6. (a) Fretting device, (b) basic sketch of a fretting conditions

\subsection{Infrared thermography}

The camera used in this study is a FLIR SC7600 MWIR 2.5-5 $\mu \mathrm{m}$. The focal length of the optical lens is $25 \mathrm{~mm}$. This camera is equipped with an InSb 640x512 element detector. The maximal frame rate, $f_{a}$, is $380 \mathrm{~Hz}$ and the noise-equivalent temperature (NET) is lower than $25 \mathrm{mK}$. The pixel size is equal to $15 \mathrm{x} 15 \mu \mathrm{m}^{2}$. The employed infrared camera should be calibrated first, this process is considered as the key parameter in the QIRT measurement. Several calibration techniques can be found in literature, such as the non-uniformity correction [19], and the radiometric artefact treatment [20]. A pixel to pixel calibration process was used in this work as in [21]. A calibration law by detector pixel is calculated, connecting the camera DL (Digital Level) to the 
temperature through a recorded constant and uniform temperature field generated by a black body (CI systems SR800R). The response of each pixel is approximated by a polynomial function as below:

$$
T(i, j)=\sum_{p=0}^{p=P} a_{p}(i, j) D L(i, j)^{p}
$$

where $p$ is the polynomial degree, $\mathrm{a}_{p}(i, j)$, DL $(i, j), \mathrm{T}(i, j)$ are respectively the calibration law coefficients, the digital level and the temperature of a pixel coordinate $(i, j)$.

Specimens are painted with a black matte paint to increase their emissivity and the lens axis of the camera is kept fixed and held perpendicular to the lateral surface of the specimens (figure 7 (a)). Given the high thermal conductivity of the steel alloys, we can assume that the observed temperature field is very close to the temperature of the contact. The temperature is then averaged over a Zone Of Interest (ZOI - figure 7 (b)). The size of this region is equal to $a \times 2 a$, where $a$ is the Hertzian contact size.

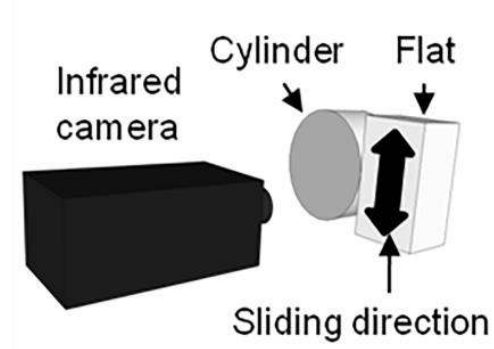

(a)

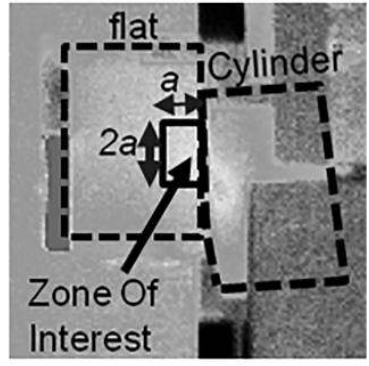

(b)

Fig. 7. (a) Basic sketch of the camera position (b) Zone Of Interest (ZOI)

\subsection{Digital image correlation}

Since the temperature is averaged over a $Z O I$ that can change from one image to another. It is essential to be able to track this change. Depending on the scale, the ZOI can be deformed, if a microscopic scale was chosen (figure 8(a)) or it can undergo a solid rigid body movement at a macroscopic one (figure 8(b)).

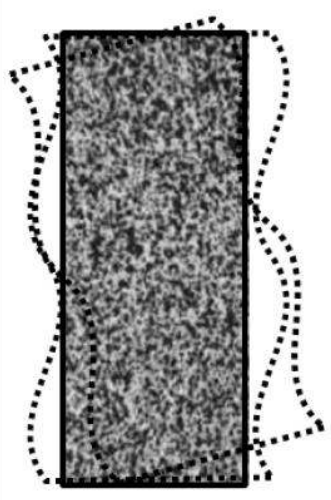

(a)

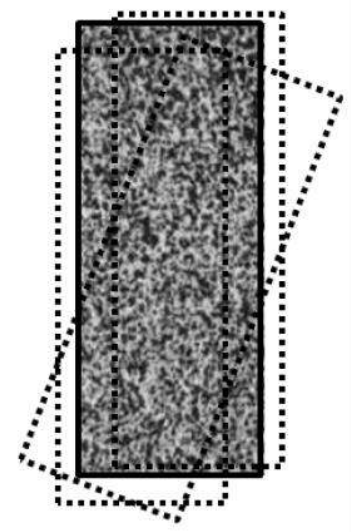

(b)

Fig. 8. Illustration of the $Z O I$ : (a) deformation, (b) solid rigid body movement

The camera used is a Redlake M5 with maximum resolution of 2336x1728 pixels. The maximal frame rate, $f_{a}$, is $340 \mathrm{~Hz}$ and the size of a pixel is equal to $7 \times 7 \mu \mathrm{m}^{2}$. For this study a macroscopic scale was chosen. At this scale, deformations of the specimen surfaces can be neglected. Only solid rigid body movement induced by the vibrations of the experimental device will be considered, and need to be corrected for a better tracking of the ZOI. To do so, Digital Image Correlation (DIC) technique was used. It gives the space-time patterns of kinematic variables such as displacement, velocity, acceleration, etc., on simple surfaces.

In-plane displacement fields of the selected ZOI were determined using an open source DIC algorithm developed at the LML (Laboratoire de Mécanique de Lille). The algorithm library is fairly rich with transformations and the users can easily add more transformations if needed. 
All images were stored digitally with two seperate computers. A matlab script is then used to process the images as follows : A $Z O I$ of $a$ x $2 a$ ( $a$, for the Hertzian contact size defined as follows $a=\sqrt{\frac{4 F R}{\pi L E} *}$, with $F$ for the normal load in N, $R$ for the cylinder radius in mm, $L$ for the specimen thickness in mm and $E^{*}$ for the equivalent young modulus in $\mathrm{MPa}$ ) is automatically selected on the IR image (figure $9(\mathrm{a})$ ), using the spatial matching function explaned above, the same zone is found on the CCD image (figure 9(b)). In-plane displacement vectors are then calculated using the DIC technique. Since the solid rigid body movements are considered, only the constuitive four corner points of the ZOI will be used (figure 9(c)), and will be implented back in the script. This will allow to track the ZOI on the IR images, and therefore a better estimation of the temperature evolution.

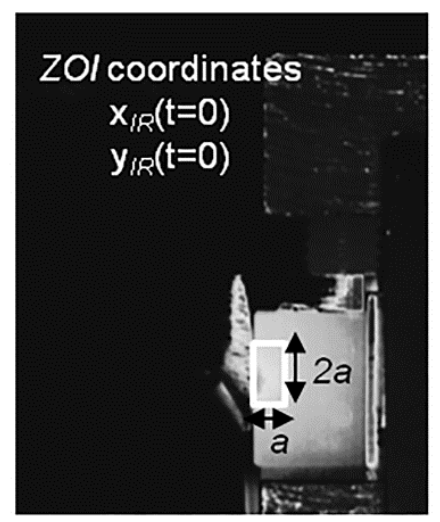

(a)

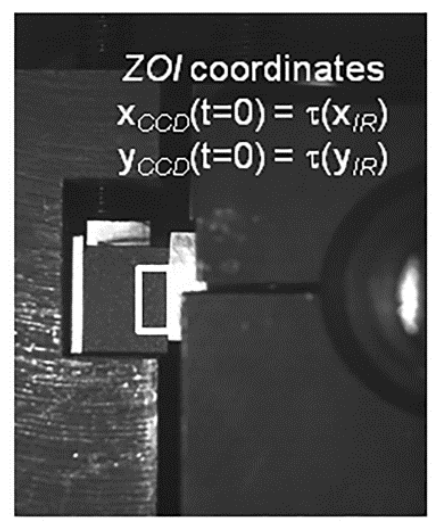

(b)

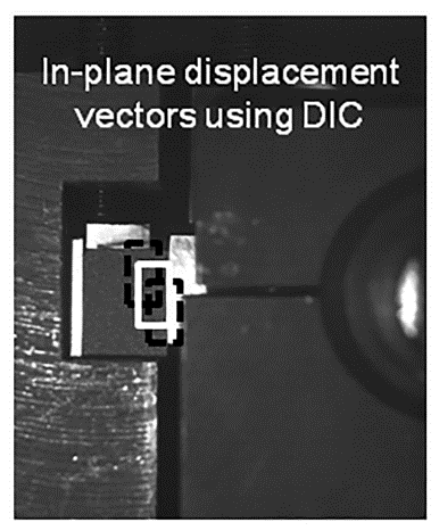

(c)

Fig. 9. Images processing: (a) ZOI selection on IR image, (b) ZOI determination using the transformation function $\tau$, (c) In-plane displacements calculation using DIC.

\subsection{Temperature evolution}

Figure 10 shows, (a) a contour plot of the temperature field and (b) the thermal response averaged over a $Z O I$ of the specimen during a simple fretting test with constant loading parameters $\left(\mathrm{R}=80 \mathrm{~mm}, p_{\max }=1000 \mathrm{MPa}\right.$, $q_{\max }=710 \mathrm{MPa}$, loading frequency $f_{L}=1 \mathrm{~Hz}$ and a camera frame rate $f_{a}=100 \mathrm{~Hz}$ ). 


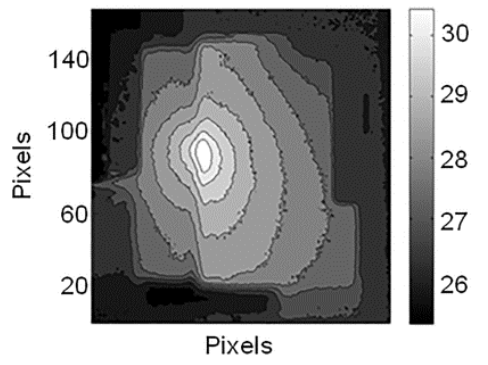

(a)

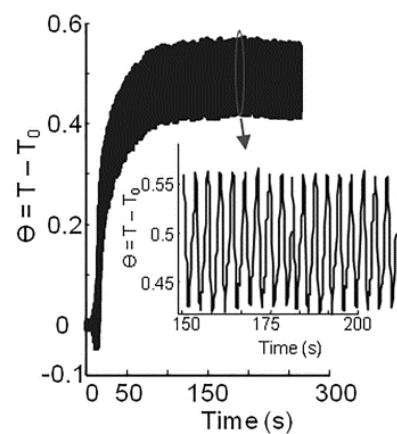

(b)

Fig. 10. Temperature variation evolution

The thermal signal can be decomposed into an overall thermal drift of about $0.5^{\circ} \mathrm{C}$, superimposed by an oscillatory variation with maximal amplitude of about $0.1^{\circ} \mathrm{C}$. A single-sided amplitude spectrum of this signal shows that the temperature evolution averaged over the $\mathrm{ZOI}$ can be decomposed into four periodic harmonics at $f_{L}, 2 f_{L}, 3 f_{L}$ and $4 f_{L}$, where $f_{L}$ is the loading frequency (figure 11 ).

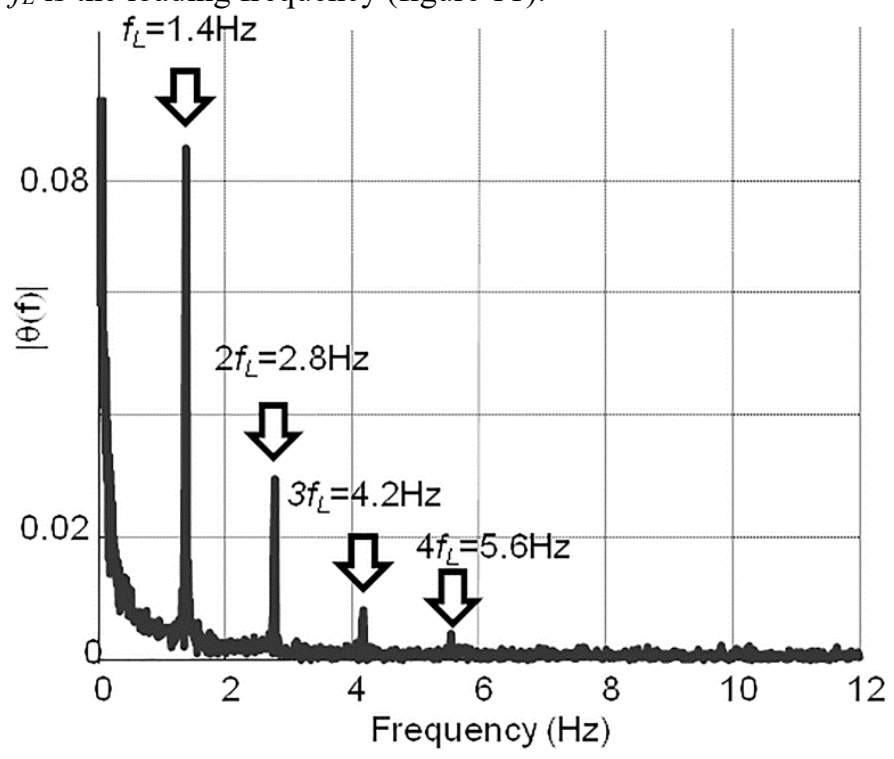

Fig. 11. Single-sided amplitude spectrum

Due to their important amplitude, only the first two periodic harmonics at $f_{L}$ and $2 f_{L}$, will be considered to define a local least-square fitting function $\theta^{\text {fit }}$ as in [3] :

$$
\begin{gathered}
\theta^{f i t}(t)=g_{1}(t)+g_{2}(t)+g_{3}(t) \\
\text { With }\left\{\begin{array}{l}
g_{1}(t)=p_{1}+p_{2} t \\
g_{2}(t)=p_{3} \cos \left(2 \pi f_{L} t\right)+p_{4} \sin \left(2 \pi f_{L} t\right) \\
g_{3}(t)=p_{5} \cos \left(4 \pi f_{L} t\right)+p_{6} \sin \left(4 \pi f_{L} t\right)
\end{array}\right.
\end{gathered}
$$

Plotted as function of the time the amplitudes of each periodic function defined as in (4) reach stabilized values $\left(\theta_{d}^{\text {sta }}, A_{f}^{\text {sta }}\right.$ and $\left.A_{2 f^{\text {sta }}}\right)$ after a few cycles (figure 12).

$$
\left\{\begin{array}{l}
\theta_{d}=p_{1} \\
A_{f}=\sqrt{p_{3}^{2}+p_{4}^{2}} \\
A_{2 f}=\sqrt{p_{5}^{2}+p_{6}^{2}}
\end{array}\right.
$$



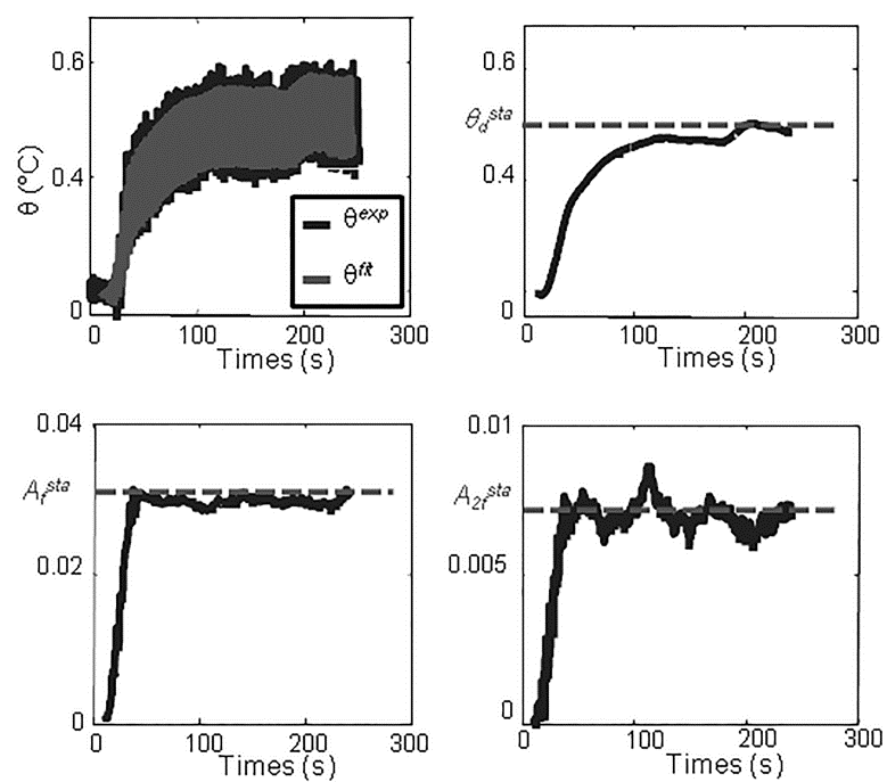

Fig. 12. Evolution of: $\theta^{\exp }, \theta^{\text {fit }}, \theta_{d}, A_{f}$ and $A_{2 f}$ threshold.

In the next section we will see how those stabilized values were used to identify the crack initiation

\subsection{Crack nucleation identification techniques}

\subsubsection{Conventional technique}

This technique consisted on testing several tangential load amplitudes, $Q_{a}$, for a given normal load $\mathrm{P}$ [2]. The tested sample is cut along the middle plane perpendicular to the fretting loading. The new surfaces are then polished and observed with an optical microscope to measure the crack length and depth (figure 13). This process is repeated at least three times in order to assess the homogeneity of the crack data.

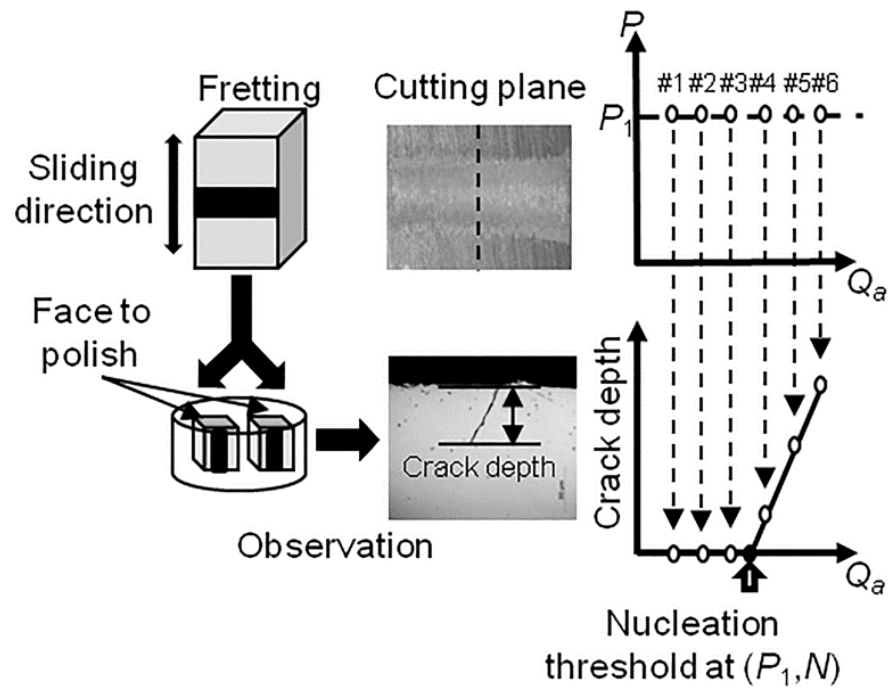

(a)

(b)

Fig. 13. Destructive crack nucleation identification technique

The maximum projected crack length $\left(\mathrm{b}_{p, \max }\right)$ is plotted as a function of the applied tangential force amplitude $Q_{a}$. The crack nucleation threshold $\mathrm{Q}_{\mathrm{d}}(d$, for destructive) is then determined by extrapolating the tangential force amplitude at $b_{p, \max }=10 \mu \mathrm{m}$ (figure 14). All the tests were performed at $10^{6}$ cycles. Between 6 to 8 tests are usually required to estimate the crack threshold and more than 100 fretting experiments were performed to cover a wild range of loadings conditions. Therefore, this method is considered as very time/material consuming. 


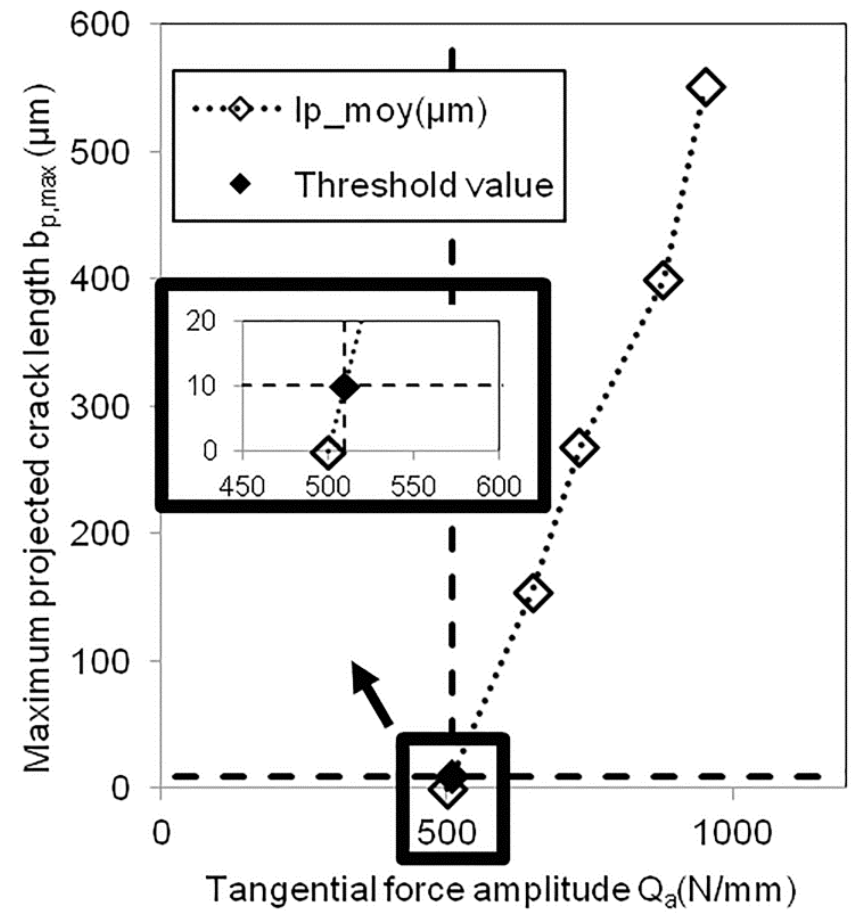

Fig. 14. Crack nucleation threshold identification for a given fretting condition $\left(R=160 \mathrm{~mm}, \mathrm{p}_{\max }=600 \mathrm{MPa}\right)$

\subsubsection{Thermal technique}

\subsubsection{Experiment}

Tests in blocks of cycles with constant maximal Hertzian pressure, $p_{\max }$, and variable relative displacement amplitude, $\delta_{a}$, are made [3]. The number of cycles per block should be sufficient to achieve temperature stabilization (at least 2000 cycles). For each block, when stabilized mechanical and thermal conditions were reached, $\delta_{a}$ was increased and then maintained constant until a new stable situation was attained. The experiments were performed at ambient temperature and different cylinder radiuses with different normal loads were tested. Table 2 shows the experimental conditions chosen for this study.

\begin{tabular}{ccccc}
\hline $\mathrm{R}(\mathrm{mm}) \backslash \mathrm{p}_{\max }(\mathrm{MPa})$ & 400 & 600 & 800 & 1000 \\
\hline 20 & & & $\mathrm{X}$ & $\mathrm{X}$ \\
40 & & $\mathrm{X}$ & $\mathrm{X}$ & $\mathrm{X}$ \\
80 & $\mathrm{X}$ & $\mathrm{X}$ & $\mathrm{X}$ & \\
160 & $\mathrm{X}$ & & \\
\hline
\end{tabular}

Table 2. Experimental conditions

As for the full field measurement, it was not practical to acquire images continuously because of the amount of data involved. Therefore, images were recorded only when temperature stabilization is reached, at a constant framing rate of 19 fps. For each block of cycles the maximal tangential force amplitude $\mathrm{Q}_{a \text {,max }}$, and the stabilized values, $\theta_{d}^{\text {sta }}, \mathrm{A}_{f}^{\text {sta }}, \mathrm{A}_{2 f}^{\text {sta }}$ are determined.

\subsubsection{Thermal crack nucleation threshold identification}

One method to evaluate the crack nucleation threshold $\mathrm{Q}_{\text {th }}$ presented in [3] is to define three offsets , $\Delta \theta_{d}, \Delta A_{f}$ and $\Delta A_{2 f}$ on a $\mathrm{Q}_{\mathrm{a}, \max }-\mathrm{V}^{\text {sta }}$ diagram $\left(\mathrm{Q}_{\mathrm{a} \text {,max }}\right.$ for the maximum amplitude of the tangential force and $\mathrm{V}^{\text {sta }}$ for the stabilized values of $\theta_{d}, A_{f}$ and $A_{2 f}$ ). In order to do so, a reference value $Q_{t h}$ obtained by the conventional method is necessary by cylinder radius. The offsets are considered to be the difference between the linear regression on the first values of the $\mathrm{V}^{\text {sta }}$ and the $\mathrm{V}^{\text {sta }}$ at the chosen reference value. Table 3 present the reference conditions chosen, as long as the values of the offsets for each cylinder radius. 


\begin{tabular}{ccccc}
\hline $\mathrm{R}(\mathrm{mm})$ & 20 & 40 & 80 & 160 \\
\hline Reference test & $\mathrm{P}_{\max }=1000 \mathrm{MPa}$ & $\mathrm{P}_{\max }=1000 \mathrm{MPa}$ & $\mathrm{P}_{\max }=1000 \mathrm{MPa}$ & $\mathrm{P}_{\max }=600 \mathrm{MPa}$ \\
$\mathrm{Q}_{\text {th }}(\mathrm{N} / \mathrm{mm})$ & 218 & 310 & 470 & 510 \\
$\Delta \theta_{d}$ & 0.09 & 0.02 & 0.3 & 0.1 \\
$\Delta A_{f}$ & 0.001 & 0.001 & 0.003 & 0.03 \\
$\Delta \mathrm{A}_{2 \mathrm{f}}$ & 0.0001 & 0.0002 & 0.0008 & 0.0009 \\
\hline
\end{tabular}

Table 3. Reference conditions with offsets values per cylinder radius.

In this work only three values $\Delta \theta_{d}^{\text {mean }}, \Delta A_{f}^{\text {mean }}$ and $\Delta A_{2 f^{\text {mean }}}$ defined as the resulting mean values of all the offsets will be considered (table 4).

\begin{tabular}{ccc}
\hline$\Delta \theta_{d}^{\text {mean }}$ & $\Delta A_{f}^{\text {mean }}$ & $\Delta A_{2 f}^{\text {mean }}$ \\
\hline 0.13 & 0.01 & 0.0005 \\
\hline
\end{tabular}

Table 4. Mean offsets values.

For all the other conditions, the maximum $\mathrm{Q}_{a, \max }$, corresponding to those offsets is considered as the $\mathrm{Q}_{I R}$ (IR for infrared), one example is presented in figure 15. It is important to note that each stabilized function $\theta_{d}{ }^{s t a}$, $\mathrm{A}_{f}^{s t a}$ and $A_{2 f}^{\text {sta }}$ gives a different value of $\mathrm{Q}_{I R}$. For a better measurement precision those values are then averaged and results will be presented in the next section.

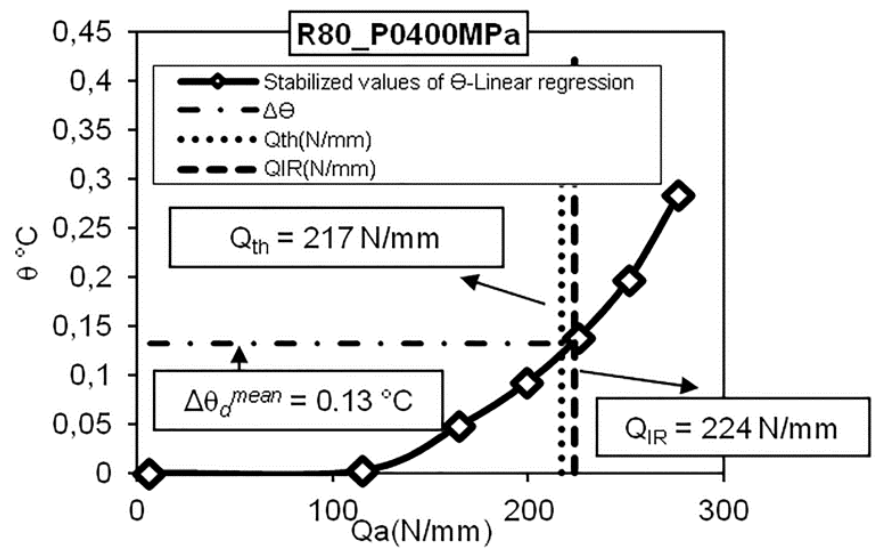

Fig. 15. An example of $\mathrm{Q}_{I R}$ identification based on $\theta_{d}^{\text {sta }}$ for $\mathrm{R}=80 \mathrm{~mm}$

It is important to understand that those thermal offsets like the temperature variation, will depend on the diffusion properties (material effect) as long as the thermal boundary conditions and the heat distribution (structure effect). Therefore, precautions like the boundary conditions must be taken into consideration when experiments are made. Nevertheless, a good correlation have been found between results of repeatable experiments.

\section{$5 \quad$ Results and discussion}

One common approach to quantify fretting cracking response consists on reporting the crack nucleation boundaries in a $Q_{a}-P$ chart $\left(\mathrm{Q}_{\mathrm{a}}\right.$ for tangential force amplitude, $\mathrm{P}$ for normal loading), or a $Q_{a}-\sigma_{f a}$ chart ( $\sigma_{\mathrm{fa}}$ for fatigue stress) for the fretting-fatigue mapping [18]. Such approach is appropriate to evaluate the effect of the normal force and the interactions between the fretting and the fatigue loadings. Fouvry et al. in [22] has developed a new approach to quantify the stress gradient effect. This approach consists on reporting the crack nucleation boundaries in a $\sigma_{f r}-P_{\max }\left(\sigma_{\mathrm{fr}}\right.$ for the contact stressing, $P_{\max }$ for the maximal Hertzian pressure). Figure 16 shows that keeping the maximum contact pressure constant; an increase in contact size due to larger cylinder radius will reduce the $\sigma_{f r}$ cracking stress. To interpret this evolution, considering Neuber's theory [21] which shows that the crack nucleation process generated in a severe stress gradient configuration is controlled by the maximum stress state but also by the volume over which this maximum stressing condition is operating. 


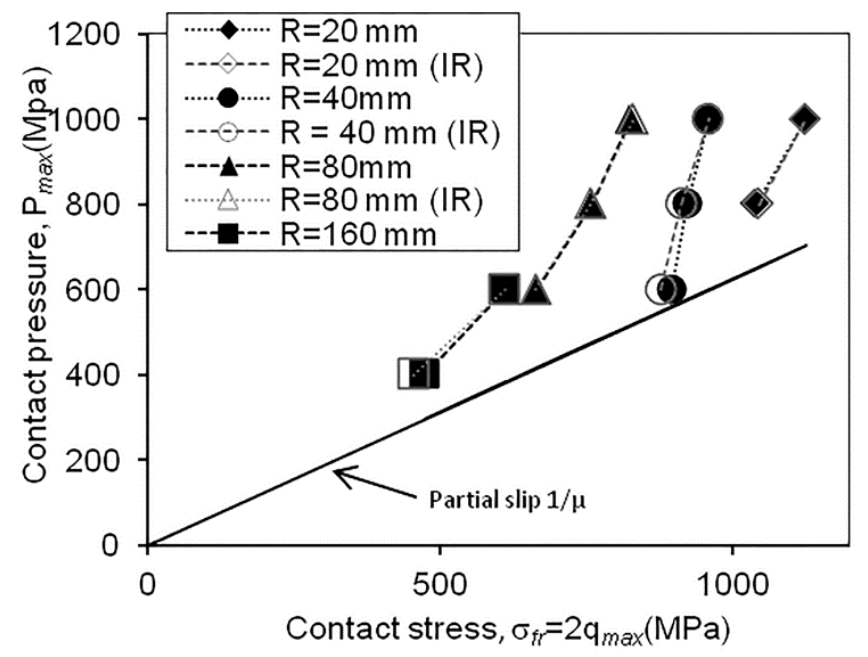

Fig. 16. $\sigma_{f r}-P_{\max }$ representation of the crack nucleation results by mean of the conventional and the thermal methods

Figure 16 shows also a close correlation between results obtained from the thermal method and those obtained from the conventional one. Table 4 present those results, along with the standard deviation (S.D.) values. The S.D. stays less than $5 \%$ for all the experimental conditions.

\begin{tabular}{ccccc}
\hline $\begin{array}{c}R \\
(\mathrm{~mm})\end{array}$ & $\begin{array}{c}P_{\max } \\
(\mathrm{MPa})\end{array}$ & $\begin{array}{c}2 q_{\text {th }}(\text { destructive }) \\
(\mathrm{MPa})\end{array}$ & $\begin{array}{c}2 q_{I R}(\text { Thermal }) \\
(\mathrm{MPa})\end{array}$ & $\begin{array}{c}\text { S.D. } \\
(\%)\end{array}$ \\
\hline 20 & 1000 & 1124.2 & 1124.2 & 0 \\
20 & 800 & 1038.4 & 1044 & 0.5 \\
40 & 1000 & 958.3 & 958.3 & 0 \\
40 & 800 & 922 & 912.3 & 1 \\
40 & 600 & 896 & 877 & 2.1 \\
80 & 1000 & 825.2 & 825.2 & 0 \\
80 & 800 & 760.3 & 757 & 0.4 \\
80 & 600 & 664.7 & 663 & 0.3 \\
160 & 600 & 611.8 & 611.8 & 0 \\
\hline
\end{tabular}

Table 4. Relative error between destructive and thermal methods.

\section{Conclusion}

In this study, a novel experimental set-up based on coupled kinematic and thermal measurements using quantitative infrared thermography (QIRT) and digital image correlation (DIC) in a two-face configuration was presented. One of the main advantages of this configuration was the flexibility to choose the surface coating separately (black coating for the thermal measurements and a speckled coating for the DIC measurements). Problems related to temporal and spatial matching of images were solved using a multi-controller and a reference target.

Unlike in [3] where a marker tracking method, with markers independent from the specimen is used. In this work, DIC technique gave in-plane displacement vectors of a Zone Of Interest (ZOI) defined on the specimen surfaces. Allowing a better tracking of the $Z O I$ and therefore a better estimation of the temperature evolution.

The thermal signal was fitted with a least-square function taking into account all the thermal harmonics. Results showed that amplitudes of the constitutive periodic functions of the fitting function reach stabilized values after few cycles and were then used to determine crack nucleation thresholds of a well known $35 \mathrm{Ni} \mathrm{Cr}$ Mo 16 low-alloyed steel under fretting loadings. Comparisons with results obtained from a conventional method were then presented and errors between both methods stayed below the $5 \%$. Unlike the conventional method where at least 6 to 8 experiments of one day each are needed to evaluate one threshold value. Only one experiment of 1 hour is needed for the thermal method. Which will reduce the time and the amount of materials used for a fretting contact characterization.

Now that it was shown that this method works on the macroscopic scale, the effort will be concentrated to undergo to a locale scale. Which allow the decoupling of thermal effects such as the intrinsic dissipation, the thermoelastic sources and dissipation due to friction. 


\section{References}

[1] D. Hoeppner, V. Chandrasekarah, and C. Elliott, Fretting fatigue: current technology and practices. American Society for Testing Materials, West Conshohocken, USA, 2000.

[2] H. Proudhon, S. Fouvry, and G. Yantio, "Determination and prediction of the fretting crack initiation: introduction of the $(\mathrm{P}, \mathrm{Q}, \mathrm{N})$ representation and definition of a variable process volume," Int. J. Fatigue, vol. 28, no. 7, pp. 707-713, Jul. 2006.

[3] B. Berthel, A.-R. Moustafa, E. Charkaluk, and S. Fouvry, "Crack nucleation threshold under fretting loading by a thermal method," Tribol. Int., vol. 76, pp. 35-44, Aug. 2014.

[4] M. P. Luong, "Fatigue limit evaluation of metals using an infrared thermographic technique," Mech. Mater., vol. 28, no. 1-4, pp. 155-163, Jul. 1998.

[5] H. Moore and JB. Kommers, "Fatigue of metals under repeated stress," Chem Met. Eng, vol. 25, pp. 4$1141,1921$.

[6] J. Krapez and D. Pacou, "Thermography detection of early thermal effects during fatigue tests of steel and aluminium samples," Brunswick,MN,US, vol. AIP, pp. 1545-1552, 2001.

[7] G. La Rosa and A. Risitano, "Thermographic methodology for rapid determination of the fatigue limit of materials and mechanical components $\square$," vol. 22, pp. 65-73, 2000.

[8] C. Doudard, M. Poncelet, S. Calloch, C. Boue, F. Hild, and a Galtier, "Determination of an HCF criterion by thermal measurements under biaxial cyclic loading," Int. J. Fatigue, vol. 29, no. 4, pp. 748757, Apr. 2007.

[9] A. Saai, H. Louche, L. Tabourot, and H. J. Chang, "Experimental and numerical study of the thermomechanical behavior of Al bi-crystal in tension using full field measurements and micromechanical modeling," Mech. Mater., vol. 42, no. 3, pp. 275-292, Mar. 2010.

[10] S. Dumoulin, H. Louche, O. S. Hopperstad, and T. Børvik, "Heat sources, energy storage and dissipation in high-strength steels: Experiments and modelling," Eur. J. Mech. - A/Solids, vol. 29, no. 3, pp. 461474, May 2010.

[11] L. Bodelot, "Étude couplée des champs cinématiques et thermiques à 1 'échelle de la microstructure des matériaux métalliques Remerciements," Univ. des Sci. Technol. Lille I, vol. Ph.D thesi, 2009.

[12] M. L. Silva and G. Ravichandran, "Combined thermoelastic stress analysis and digital image correlation with a single infrared camera," J. Strain Anal. Eng. Des., vol. 46, pp. 241-255, 2011.

[13] A. Maynadier, M. Poncelet, K. Lavernhe-Taillard, and S. Roux, "One-shot Measurement of Thermal and Kinematic Fields: InfraRed Image Correlation (IRIC),” Exp. Mech., vol. 52, no. 3, pp. 241-255, Mar. 2011.

[14] A. Chrysochoos, B. Berthel, F. Latourte, A. Galtier, S. Pagano, and B. Wattrisse, "Local energy analysis of high-cycle fatigue using digital image correlation and infrared thermography," J. Strain Anal. Eng. Des., vol. 43, no. 6, pp. 411-422, 2008.

[15] A. Chrysochoos, B. Berthel, F. Latourte, S. Pagano, B. Wattrisse, and B. Weber, "Local Energy Approach to Steel Fatigue," Strain, vol. 44, no. 4, pp. 327-334, Aug. 2008.

[16] A. Chrysochoos, V. Huon, F. Jourdan, J. M. Muracciole, R. Peyroux, and B. Wattrisse, "Use of full-field digital image correlation and infrared thermography measurements for the thermomechanical analysis of material behaviour," Strain, vol. 46, no. 1, pp. 117-130, 2010.

[17] S. Fouvry, P. Kapsa, F. Sidoroff, and L. Vincent, "Identification of the characteristic length scale for fatigue cracking in fretting contacts,” J. Phys. IV Fr., vol. 8, pp. 66-159, 1998. 
[18] H. Proudhon, S. Fouvry, and J. Buffiere, "A fretting crack initiation prediction taking into account the surface roughness and the crack nucleation process volume," Int. J. Fatigue, vol. 27, no. 5, pp. 569-579, May 2005.

[19] M. Schulz and L. Caldwell, "Nonuniformity correction and correctability of infrared focal plane arrays," Infrared Phys. Technol., vol. 36, no. 4, pp. 763-777, Jun. 1995.

[20] M. Poncelet, J.-F. Witz, H. Pron, and B. Wattrisse, “A study of IRFPA camera measurement errors: radiometric artefacts,” Quant. Infrared Thermogr. J., vol. 8, no. 1, pp. 3-20, Jun. 2011.

[21] V. Honorat, S. Moreau, J.-M. Muracciole, B. Wattrisse, and a. Chrysochoos, "Calorimetric analysis of polymer behaviour using a pixel calibration of an IRFPA camera," Quant. Infrared Thermogr. J., vol. 2, no. 2, pp. 153-171, Dec. 2005.

[22] S. Fouvry, H. Gallien, and B. Berthel, "From uni- to multi-axial fretting-fatigue crack nucleation: Development of a stress-gradient-dependent critical distance approach," Int. J. Fatigue, vol. 62, pp. 194209, May 2014. 